\title{
Exploring spatiotemporal changes in ecosystem-service values and hotspots in China
}

\author{
Guangdong Li ${ }^{\mathrm{a}, \mathrm{b}}$, Chuanglin Fang ${ }^{\mathrm{a}, \mathrm{b}, *}$, Shaojian Wang ${ }^{\mathrm{c}, * *}$ \\ a Institute of Geographic Sciences and Natural Resources Research (IGSNRR), Chinese Academy of Sciences (CAS), 11A Datun Road, Chaoyang District, Beijing 100101, China \\ ${ }^{\mathrm{b}}$ Key Laboratory of Regional Sustainable Development Modeling, Chinese Academy of Sciences (CAS), Beijing 100101, China \\ c Guangdong Provincial Key Laboratory of Urbanization and Geo-simulation, School of Geography and Planning, Sun Yat-sen University, Guangzhou 510275, China
}

\section{H I G H L I G H T S}

- We examine changes in terrestrial ecosystem services values and their hotspots in China.

- The tendency of ecosystems in China to gradually deteriorate.

- The variations in terrestrial ESV change have spatial heterogeneity.

- Ecological conservation programs have a positive ecological effect on China's ecosystems.

\section{G R A P H I C A L A B S T R A C T}

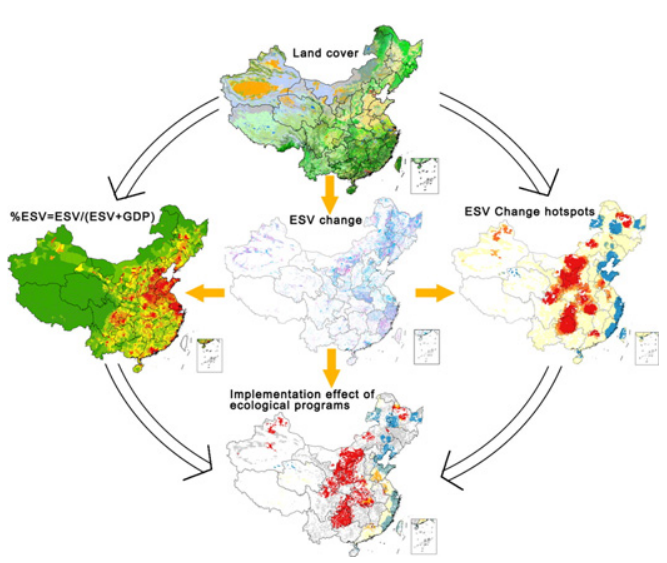

\begin{abstract}
A B S T R A C T
Although ecosystems are valuable, they have been allowed to deteriorate globally in recent decades. However, the spatiotemporal changes in ecosystem-service values (ESVs) and their hotspots in China are not well understood. Here, long-term land-cover data, the spatial analysis method and an econometric analysis model were used to examine these changes. The results indicate that the total terrestrial ESV decreased from US\$2398.31 billion in 1990 to US $\$ 2347.56$ billion in 2010 (converted to 2009 dollar values), which provides strong evidence for the tendency of ecosystems in China to deteriorate over time, albeit slightly. We also found that the changes in ESVs had significant spatial heterogeneity. Our analysis showed that the relationship between ESV and gross domestic product (GDP) is generally negative, but this relationship is not always fixed. The Loess Plateau, Guizhou, Hubei, Henan and Xinjiang continually presented concentrated hotspot areas of ESV changes, whereas coastal regions continually presented concentrated cold-spot areas. Overlap analyses and logistic regressions demonstrate that national ecological programs have clear effects on the improvement of ecosystems but that the effectiveness of different policies varies on spatial and temporal scales. The results of this study will support more effective decision-making around the implementation of ecological conservation policies.
\end{abstract}

(C) 2015 Elsevier B.V. All rights reserved.

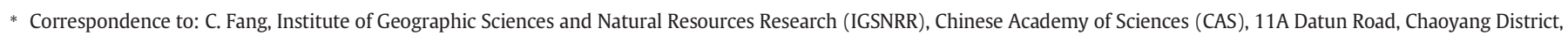
Beijing 100101, China.

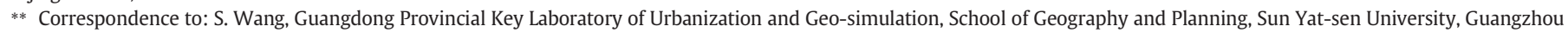
510275, China.

E-mail addresses: fangcl@igsnrr.ac.cn (C. Fang), 1987wangshaojian@163.com (S. Wang).
} 


\section{Introduction}

Ecosystems provide a multitude of services that are of fundamental significance to humans' well-being, livelihood, health and survival (Costanza et al., 1997, 2014; Millennium Ecosystem Assessment, 2005; TEEB, 2010a, b). The importance of these services has stimulated considerable interest in their conservation. After the seminal work of Costanza et al. (1997), the body of research on methods of estimating, mapping, and quantifying ecosystem services has grown exponentially (Fisher et al., 2009), particularly since the release of the Millennium Ecosystem Assessment (MA; de Groot et al., 2010, 2012), an international study involving over 1300 scientists. The MA provided important evidence of the ongoing degradation of approximately $60 \%$ of the world's ecosystems over the past five decades (Millennium Ecosystem Assessment, 2005). The Economics of Ecosystems and Biodiversity (TEEB), an international initiative, further confirmed this global trend of ecosystem deterioration and provided a scientific foundation to help decision makers recognize, demonstrate and capture the values of ecosystems (TEEB, 2010a). Currently, hundreds of projects and groups around the world are generating additional data on ecosystem services and on improving modeling, mapping, valuation, and management techniques stimulated by the aforementioned programs.

Most research on the valuation of ecosystems services is focused on monetizing and estimating explicit ecosystem-service values (ESVs) at a certain point in time (Costanza et al., 1997; Li and Fang, 2014; Sutton and Costanza, 2002). Although temporal changes in ESVs are as important or even more important, monitoring change over a longer time scale has rarely been performed on global, national or regional scales; however, this topic has attracted scholarly attention in recent years (Costanza et al., 2014; Su et al., 2012a). For example, Costanza et al. estimated that the global loss of ESV from 1997 to 2011 caused by land-use changes was \$4.3-20.2 trillion/yr (Costanza et al., 2014). Kreuter et al. (2001) and Su et al. (2012b) quantified variations in ESV in response to land-use changes on regional and eco-regional scales. Kreuter et al. (2001) reported a $4 \%$ net decline in the estimated annual value of ecosystem services between 1976 and 1991 in San Antonio, the United States. Su et al. (2012b) found that considerable urban expansion led to a loss of 8.5 billion RMB yuan ecosystem-service values per year on average between 1994 and 2003 in the Hang-Jia-Hu ecoregion of China. Furthermore, the number of studies on this topic on local scales has grown rapidly (Hu et al., 2008; Li et al., 2007; Zhao et al., 2004). Based on the aforementioned literature, we found that basic benefit transfer (assuming a constant unit value per hectare of a given ecosystem type multiplied by the area of each type to arrive at an aggregate total (Costanza et al., 2014)) is still a simple and easy method of determining ESVs on global and national scales.

Although developing a greater understanding of temporal changes in ESVs is important, increasing interest has been focused on determining how ESVs change spatially by identifying 'hotspots' of ecosystem services that are important for biodiversity and provide multiple ecosystem services (Chan et al., 2006; Egoh et al., 2009; Naidoo et al., 2008; Turner et al., 2007). These spatial studies may provide a series of useful tools that can effectively integrate ecosystem services into planned or current conservation programs (Naidoo et al., 2008), assess the effects of implementing ecological policies, and identify priority areas for ecosystem-service management (Egoh et al., 2011). Such information is particularly important to allow for the modification of current ecological conservation planning and policies in a more beneficial and targeted way. However, hotspots of ESV changes on specific spatial scales, particularly global and national scales, are poorly characterized.

The initiation of economic reforms in China in 1978 promoted rapid economic growth, urbanization and industrialization and transformed a population of 1.3 billion people from a largely agrarian society into an industrial economy (He et al., 2014). This rapid development had a significant influence on land use and cover changes (LUCCs) and ESV changes (Liu et al., 2010) and led to an increasingly deteriorating environment in China (Liu et al., 2008). Recent literature has documented the negative effects (e.g., environmental pollution, soil erosion, natural disasters) on ecosystems that are associated with this rapid economic development (Diao et al., 2009; He et al., 2014; Liu et al., 2008). To improve human well-being and to change the deterioration of ecology and the environment, the Chinese government has implemented a number of national programs on ecosystem-service conservation, such as the Key Shelterbelt Construction Program (KSCP), the Natural Forest Conservation Program (NFCP), the Grain to Green Program (GTGP), the Beijing-Tianjin Sandstorm Control Program, the Wildlife Conservation and Nature Reserve Development Program, and the Forest EcoCompensation Program (Liu et al., 2008). These programs also provide additional opportunities to understand national concerns about ecosystem-service issues.

The availability of land-cover data is a key factor when undertaking a long temporal-scale analysis of ESVs at the national level. However, the limitedness of the available long-term land-cover data for China has increased the difficulty of investigating national change in ESVs (but a land-cover change database during 1990-2010 developed by Chinese Academy of Sciences is an exception). In addition to issues with available data, determining unit values of ecosystem services remains a challenge. Although relevant studies have focused on the dynamic changes in ESVs in China on regional, city or county scales (Fang et al., 2014; Hu et al., 2008; Li et al., 2007, 2010a, b; Wan et al., 2015; Zhao et al., 2004), national investigations are still lacking. However, aggregates of these data to form a national picture can be used to revise national income figures (Costanza et al., 2014). Identifying hotspots of ESV change on a national scale satisfies the requirements for applying dedicated programs and policies. For decision makers, identifying hotspot and cold-spot areas of ESV change is a more practical method of testing the effect of implementing related policies and programs for ecological conservation and adjusting the direction of programs in the future.

In this paper, we investigated the spatiotemporal changes in ESV, examined the relationships between ESV and gross domestic product (GDP), identified hotspot and cold-spot areas of ESV change and tested the effects of implementing ecological conservation programs in China. This analysis was based on long-term continuous land-cover data for China for the period from 1990 to 2010, and it incorporated landcover data, the TEEB dataset, the Hot Spot Analysis (Getis-Ord Gi*) tool and a logistic regression model.

\section{Materials and methods}

\subsection{Study area and land-cover data}

Land-cover data are used to estimate the ESV and to identify the hotspots of ESV change. Land-cover data on a long time scale provide the foundation for studies of ESV change and effective decision-making support for conservation projects. The land-cover dataset (1-km resolution) of used in this paper included five continuous periods (1990-1995, 1995-2000, 2000-2005 and 2005-2010; Fig. 1). It was produced by the Chinese Academy of Sciences (CAS, http://www.geodata.cn/) using an integrated method of the automatic classification method and manual interpretation method for remote-sensing images. Landsat MSS/TM/ETM, the China-Brazil Earth Resources Satellite (CBERS), HJ-1 (a small satellite constellation for environmental and disaster monitoring) and Moderate Resolution Imaging Spectroradiometer (MODIS) remote-sensing images were the primary data sources. Land-cover types were divided into 6 categories and 25 sub-categories. The total accuracy rate of land-cover classification exceeded $80 \%$, as verified by a host of field surveys. This is the newest and most detailed land-cover dataset on the national scale in China (Liu et al., 2003, 2010). 


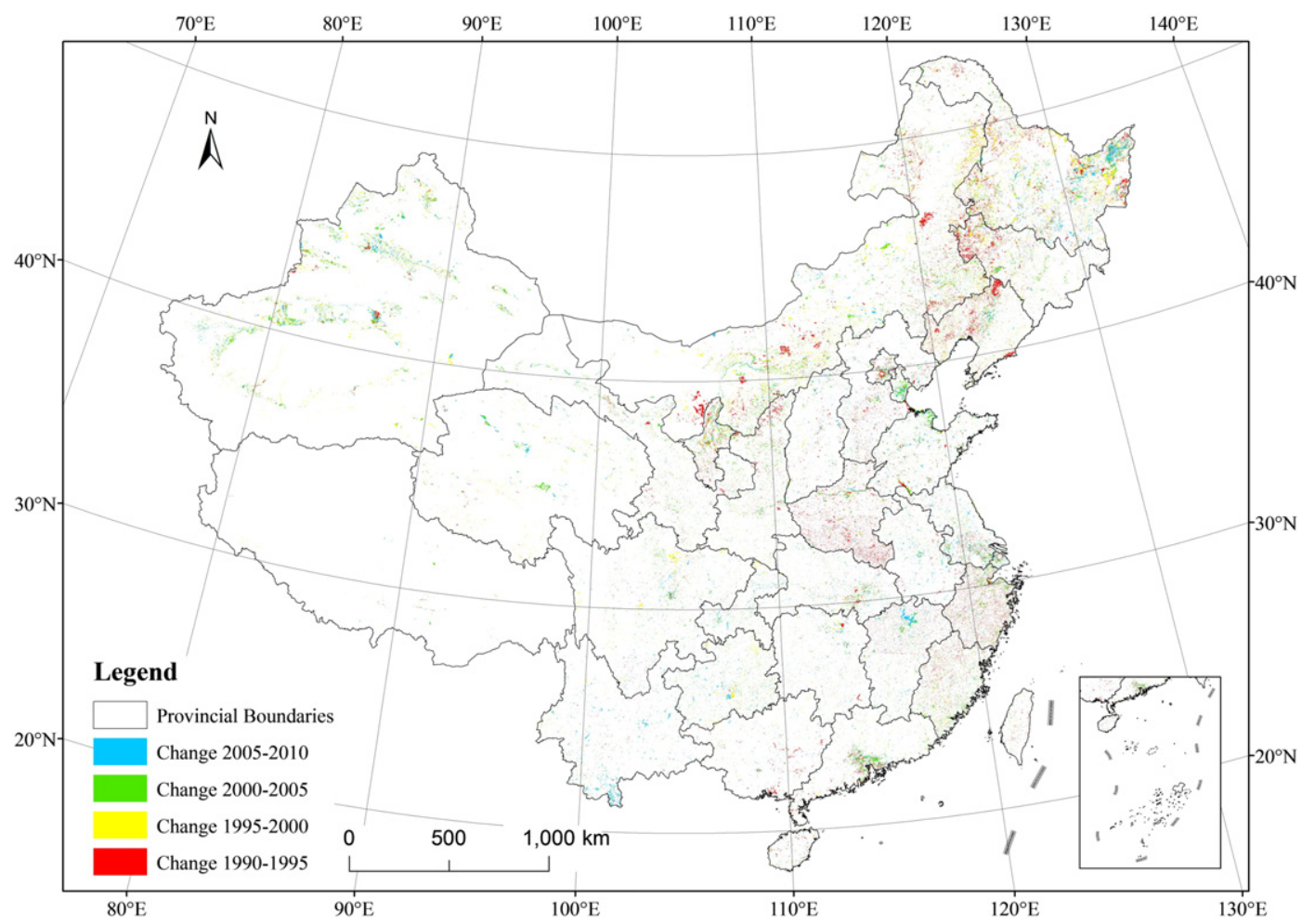

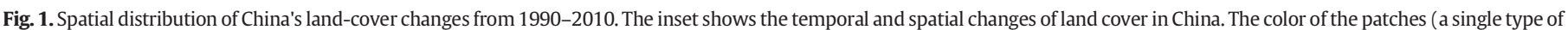

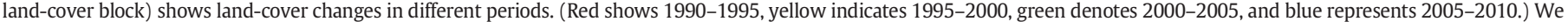

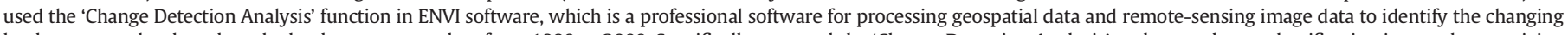

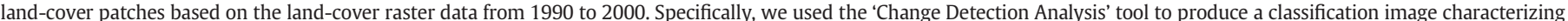

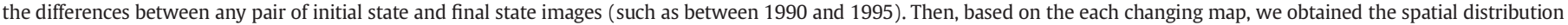
map of the land-cover changes from 1990-2010.

\subsection{Estimating ESV from land-cover data}

We referred to Costanza's ESV assessment method (Costanza et al., 1997) to calculate ESVs. The following model was used:

$E S V=\sum\left(A_{k} \times V C_{k}\right)$

where $E S V$ is the total value of ecosystem services, and $A_{k}$ (ha) and $V C_{k}$ (US\$/ha) represent the area and monetary value unit for landcover class ' $k$ ', respectively. In this model, the value of $A_{k}$ was obtained from the aforementioned land-cover data using ArcGIS 10.2 software. A Zonal Statistics tool was applied to calculate area of each land-cover type at the county level. (The total national value was obtained from an aggregation.) Thus, $V C_{k}$ is an extremely important parameter in this model. Fundamental information on the $V C_{k}$ was sourced from a number of databases, including the COPI Valuation database (Braat et al., 2008 and ENVAlue, 2004), ESD-ARIES (UVM, 2008), ValueBaseSwe (Sundberg and Söderqvist, 2004), and EcoValue (Wilson et al., 2004), along with other relevant studies with data on ecosystem-service values (e.g., Costanza et al., 1997; De Groot et al., 2002; Brander et al., 2006). Strict criteria were followed for data selection. Then, we obtained a summary of the monetary values for each service per biome, which were presented as 'averages'. de Groot et al. (2012) provide a detailed description of this procedure. Here, to obtain a more comprehensive unit value for ecosystem services, we upgraded the previous Ecosystem Service Valuation Database (ESVD; de Groot et al., 2012). We used more recent information with the same ESVD procedure. A total of 723 value estimates (including 22 ecosystem functions from TEEB categories (TEEB, 2010a)) in the dataset were used for the analysis (665 from the previous ESVD). We also extended the ecosystem classification of ESVD combined with the characteristics of the land-cover data for
China. Cultivated land (including paddy land, irrigated land and dry land) and human settlements (including urban and built-up land and rural residential land) were included in our study; thus, we did not focus only on non-human-dominant systems. Desert and permanent snow and ice were excluded from our valuation because of the limited number of value cases. To our knowledge, this is one of the largest datasets of ESV values ever collected. The ESVs and functions were translated into 2009 international US\$ values based on purchasing power parity (PPP). This unit value was also adjusted to match China's land-cover class. Finally, the unit value's corresponding ESV was used to calculate the total ESV for each land-cover class, which was multiplied by the area of each land-cover class.

\subsection{The relationship between ESV and GDP}

We used spatiotemporal information on the ESVs and GDP to understand the distribution pattern of ESVs and GDP and corresponding combination law. To examine and understand the relationship between ESVs and GDP, we developed a simple indicator, \%ESV, based on Sutton and Costanza (2002). This index has good applicability and can be used on various spatiotemporal scales; in this paper, the index was applied at the national and county levels. The \%ESV is a measure of the proportion of ESV from ESV + GDP:

$$
\% \mathrm{ESV}=\mathrm{ESV} /(\mathrm{ESV}+\mathrm{GDP}) \times 100 \%
$$

\subsection{Hotspot and cold-spot analyses of ESV change}

Hotspot analyses are widely applied in socio-economic analyses and ecological analyses, and they were used here to identify the locations of statistically significant hotspots and cold spots in our data. Hotspots and 
cold spots are statistically significant spatial clusters of high values and low values, respectively. In this paper, ArcGIS 10.2 software was used to explore the hotspots and cold spots of ESV changes. Using the following steps, we obtained the distribution of hotspots and cold spots for ESV changes.

Step 1: ArcGIS software was used to identify changing patches of land-cover data. A single ESV value was assigned to each patch, which equaled the $V C_{k}$ value corresponding to its land-cover class, and the ESV change for each of the patches between the two years was calculated. Considering the feasibility and flexibly of spatial analysis, we converted changing land-cover patches into points (because point data can be used flexibly and provide enhancing visualizations). Using the Feature to Point tool in ArcGIS, we converted the patch layer into the point layer (The output point was located at the center of gravity (the centroid) of the patch).

Step 2: We used the Hot Spot Analysis (Getis-Ord Gi*) tool to identify the hotspots and cold spots of these changing value points. The Hot Spot Analysis tool calculates the Getis-Ord Gi* statistic (pronounced $\mathrm{G}$-i-star) for each changing land-cover point converted by changing patches. The resulting $\mathrm{z}$-scores and $\mathrm{p}$-values indicated where features with either high or low values were clustered spatially. (The p-value is a probability, and Z-scores are simply standard deviations; 0.01, 0.05 and 0.1 are typical probabilities, and $<-1.65$ or $>+1.65,<-1.96$ or $>+1.96$ and $<-2.58$ or $>+2.58$ are critical z-scores for 90,95 and $99 \%$ confidence levels, respectively.)

\subsection{Assessment of implementation effects for national conservation policies for ecosystem services}

According to authoritative planning maps and statistical tables (http://www.forestry.gov.cn/), we vectorized the targeted areas of the KSCP, NFCP and GTGP, which was supported by the ArcGIS 10.2 software. The Overlay Analysis tool was used to aggregate overlapping areas between hotspots of ESV changes and targeted areas of these policies. Then, we used a binary logistic regression to further examine the effectiveness of the implemented programs. $Y$ is a binary response variable; $Y_{i}=1$ if the hotspot of ESV changes and the targeted area of a policy is coincident in observation $i$; and $Y_{i}=0$ if the coincident is not present in observation $i . X=\left(X_{1}, X_{2}, \ldots, X_{\mathrm{k}}\right)$ is set of explanatory variables that can be discrete, continuous, or a combination of the two. $x_{\mathrm{i}}$ is the observed value of the explanatory variables for observation $i$. The binary logistic regression model was formed as follows:

$\pi_{i}=\operatorname{Pr}\left(Y_{i}=1 \mid X_{i}=x_{i}\right)=\frac{\exp \left(\beta_{0}+\beta_{1} x_{i}\right)}{1+\exp \left(\beta_{0}+\beta_{1} x_{i}\right)}$

or

$\operatorname{logit}\left(\pi_{i}\right)=\log \left(\frac{\pi_{i}}{1-\pi_{i}}\right)=\beta_{0}+\beta_{1} x_{i}=\beta_{0}+\beta_{1} x_{i 1}+\ldots+\beta_{k} x_{i k}$

$Y_{i}$ is called a Bernoulli distribution with parameter $\pi_{i}$; i.e., a binary logistic regression model assumes a binomial distribution of the response. $\beta_{0}$ is the intercept, and $\beta_{1}$ is a vector of regression coefficients. The dependent variable was a binary vector coded as 1 (hotspots, $\mathrm{P}<0.1$ ) or 0 (no hotspots, $\mathrm{P}>0.1$ ). For each time period, we designed a targeted logistic regression model. The explanatory variables were the targeted areas ( 1 for targeted areas, 0 for non-targeted areas) of the KSCP (for four periods), NFCP (2000-2005 and 2005-2010) and GTGP (20002005 and 2005-2010). All calculations were performed using IBM software SPSS Statistics 22.

\section{Results}

\subsection{Temporal change in the terrestrial ESVs of China for 1990-2010}

We first examined changes in the terrestrial ESVs in China using the simple benefit-transfer method, which is estimated by multiplying the land area for each category by the unit value. This analysis revealed a slightly decreasing trend in terrestrial ESV overall for 1990-2010. Table 1 shows that the total ESV decreased from $\$ 2398.31$ billion in 1990 to $\$ 2347.56$ billion in 2010 (converted to 2009 dollar values), which represents a significant loss rate of $\$ 2.54$ billion per year. This decrease can be attributed to slight land-cover changes during the study period. The overall land-cover characteristics did not change despite the rapid economic growth process experienced during this period.

Compared with the other analyzed periods, the terrestrial ESV from 1990 to 1995 displayed a larger loss ( $\$ 17.425$ billion/yr), which was primarily caused by decreases in coastal and inland wetland areas. Of all 25 land-cover types, the values of twelve land-cover types, particularly broadleaf evergreen trees, needle-leaved evergreen trees and inland water bodies, increased during this period (accounting for $\$ 4.721$ billion/yr). However, these increases were mitigated by large decreases in the values of eleven land-cover types (accounting for $\$ 22.146$ billion/yr). From 1995 to 2000, the terrestrial ESVs displayed a small loss ( $\$ 3.674$ billion/yr), which was primarily caused by an increase in coastal wetland area. However, the value of inland wetlands exhibited a decreasing trend. From the perspective of ESV change, we found that twelve ecosystems experienced ongoing deterioration from 1995 to 2000. From 2000 to 2005, terrestrial ESVs showed the largest loss ( $\$ 20.256$ billion/yr), which was largely because of decreases in the area of high-value-per-ha ecosystems (coastal and inland wetlands) and increases in low-value-per-ha ecosystems (urban ecosystem and irrigated land). From 2005 to 2010, the net decrease in ESV was estimated at $\$ 9.395$ billion/yr. Thus, ecosystem conditions will likely continue to worsen because the values of fifteen ecosystems have been decreasing (approximately 65\% of ecosystem types) for the two assessed periods between 2000 and 2010.

\subsection{Spatial distribution characteristics of changing terrestrial ESVs}

Data from 1990 to 2010 were analyzed using ArcGIS 10.2 software, and a change graph of the spatial distribution of changes in ESV over the past two decades was created. The results showed that variations in terrestrial ESV change in China had salient regional characteristics; in particular, these changing regions are unevenly distributed (Fig. 2).

From 1990 to 1995, the greatest total changes in terrestrial ESV were observed. Fig. 2a shows that the value of terrestrial ESVs in most regions decreased in closely grouped areas. In addition, the regions in which ESVs increased the most over time were also groups. It is interesting that the ESV in northeast China, Inner Mongolia, and Ningxia, Henan, Zhejiang and Fujian Provinces displayed a large decline in scale, and these regions also witnessed a synchronous increase in ESV, which indicates that significant adjacency occurred in land areas whose value increased and decreased or in areas that are spatially adjacent. It is said that these regions are both the increased areas of value for some ecosystems types and the decreased areas of value of some ecosystem types. Land-cover changes are a mixed process of different land-cover types with a high ESV value and a low ESV value. From 1995 to 2000, the change in the land area was not apparent compared with that of the prior period (Fig. 2b). The regions where the ESVs increased tended to have a scattered spatial distribution. From 2000 to 2005, the ESV in most regions, including areas in northeast China, Inner Mongolia, the Beijing-Tianjin-Hebei region, the Yangtze River Delta and the Pearl River Delta (Fig. 2c), significantly declined. Areas with increased ESV were distributed in the Loess Plateau, the Chongqing Municipality and the Guizhou 
Table 1

Land-cover changes, unit values of ecosystem services and aggregate terrestrial ESV from 1990 to 2010 in China.

\begin{tabular}{|c|c|c|c|c|c|c|c|c|c|c|c|}
\hline \multirow[t]{2}{*}{ Land-cover classes } & \multicolumn{5}{|c|}{ Area (ten thousand $\mathrm{km}^{2}$ ) } & \multirow{2}{*}{$\begin{array}{l}\text { Unit values of ecosystem } \\
\text { services (\$/ha, 2009) }\end{array}$} & \multicolumn{5}{|c|}{ Aggregate ecosystem-service value (billion \$, 2009) } \\
\hline & 1990 & 1995 & 2000 & 2005 & 2010 & & 1990 & 1995 & 2000 & 2005 & 2010 \\
\hline Needle-leaved evergreen trees & 51.00 & 51.22 & 51.05 & 51.10 & 51.04 & 3135 & 159.88 & 160.59 & 160.05 & 160.20 & 160.02 \\
\hline Broadleaf evergreen trees & 42.81 & 43.10 & 43.05 & 43.01 & 43.01 & 5474 & 234.32 & 235.94 & 235.65 & 235.42 & 235.42 \\
\hline Needle-leaved deciduous trees & 15.02 & 15.04 & 14.95 & 14.98 & 15.02 & 3135 & 47.09 & 47.14 & 46.85 & 46.95 & 47.08 \\
\hline Broadleaf deciduous trees & 43.52 & 43.19 & 42.90 & 43.00 & 43.06 & 3135 & 136.42 & 135.41 & 134.49 & 134.80 & 135.00 \\
\hline Mixed needle-leaved and broadleaf trees & 27.63 & 27.63 & 27.45 & 27.41 & 27.44 & 4305 & 118.95 & 118.93 & 118.17 & 117.98 & 118.12 \\
\hline Shrub & 47.28 & 47.30 & 47.17 & 47.26 & 47.16 & 1652 & 78.10 & 78.14 & 77.92 & 78.07 & 77.91 \\
\hline Meadow & 47.30 & 47.01 & 46.46 & 46.06 & 45.84 & 2452 & 115.98 & 115.26 & 113.92 & 112.94 & 112.40 \\
\hline Grassland & 65.06 & 64.70 & 64.43 & 64.23 & 64.11 & 2186 & 142.21 & 141.43 & 140.85 & 140.40 & 140.14 \\
\hline Desert grassland & 51.32 & 51.02 & 50.66 & 50.33 & 50.23 & 1652 & 84.78 & 84.28 & 83.68 & 83.14 & 82.98 \\
\hline Alpine meadow & 66.61 & 66.62 & 66.61 & 66.58 & 66.58 & 2986 & 198.91 & 198.92 & 198.90 & 198.82 & 198.80 \\
\hline Alpine steppe & 48.31 & 48.49 & 48.46 & 48.40 & 48.40 & 2986 & 144.26 & 144.79 & 144.71 & 144.52 & 144.54 \\
\hline Shrub grassland & 17.54 & 17.18 & 17.24 & 17.14 & 17.05 & 1652 & 28.97 & 28.39 & 28.49 & 28.31 & 28.17 \\
\hline Paddy land & 47.77 & 47.54 & 47.75 & 46.80 & 46.29 & 2048 & 97.83 & 97.36 & 97.78 & 95.84 & 94.80 \\
\hline Irrigated land & 53.15 & 53.38 & 53.69 & 54.29 & 54.39 & 1205 & 64.05 & 64.32 & 64.70 & 65.41 & 65.54 \\
\hline Dry land & 78.02 & 78.38 & 79.08 & 78.76 & 78.22 & 1205 & 94.02 & 94.45 & 95.29 & 94.91 & 94.26 \\
\hline Urban and built-up land & 3.93 & 4.61 & 4.86 & 6.23 & 7.88 & 240 & 0.94 & 1.11 & 1.17 & 1.50 & 1.89 \\
\hline Rural residential land & 12.16 & 12.49 & 12.75 & 13.02 & 13.31 & 240 & 2.92 & 3.00 & 3.06 & 3.12 & 3.19 \\
\hline Inland wetland & 11.92 & 11.75 & 11.66 & 11.47 & 11.42 & 26,708 & 318.23 & 313.71 & 311.31 & 306.32 & 304.94 \\
\hline Coastal wetland & 0.69 & 0.62 & 0.63 & 0.56 & 0.53 & 201,598 & 138.36 & 125.15 & 126.78 & 113.46 & 107.59 \\
\hline Inland water bodies & 14.91 & 15.06 & 15.20 & 15.65 & 15.63 & 4438 & 66.17 & 66.84 & 67.47 & 69.46 & 69.35 \\
\hline Beaches of rivers and lakes & 5.02 & 4.88 & 4.96 & 4.73 & 4.92 & 1652 & 8.30 & 8.06 & 8.19 & 7.82 & 8.13 \\
\hline Permanent snow and ice & 6.87 & 6.87 & 6.87 & 6.88 & 6.87 & 0 & 0.00 & 0.00 & 0.00 & 0.00 & 0.00 \\
\hline Bare rock & 125.69 & 125.86 & 125.88 & 125.75 & 125.66 & 826 & 103.82 & 103.96 & 103.98 & 103.87 & 103.80 \\
\hline Bare land & 16.70 & 16.61 & 16.68 & 16.59 & 16.33 & 826 & 13.79 & 13.72 & 13.78 & 13.70 & 13.49 \\
\hline Desert & 50.26 & 49.95 & 50.03 & 50.28 & 50.09 & 0 & 0.00 & 0.00 & 0.00 & 0.00 & 0.00 \\
\hline Total & 950.48 & 950.48 & 950.48 & 950.48 & 950.48 & - & 2398.31 & 2380.88 & 2377.21 & 2356.95 & 2347.56 \\
\hline
\end{tabular}

Province. From 2005 to 2010, the areas with decreasing ESVs showed a spatial pattern similar to that of the former period, with coastal and central regions showing significant decreases in area on a large scale (Fig. 2d). For areas with increasing ESV, more of a scattered pattern was observed, with the Sanjiang Plain and southern Yunnan presenting increased values on a large scale.

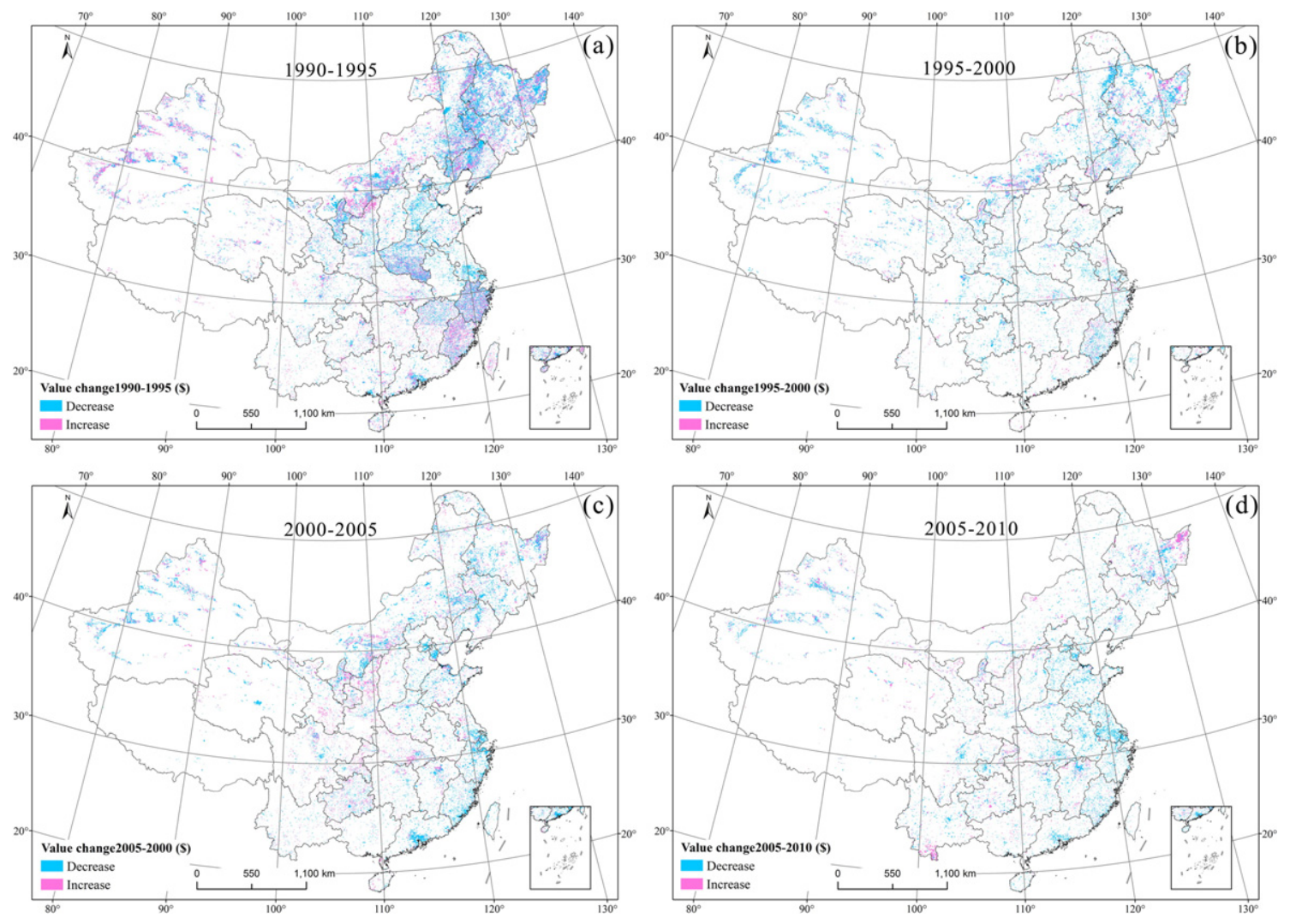

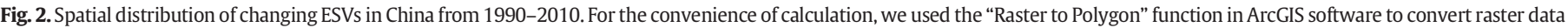

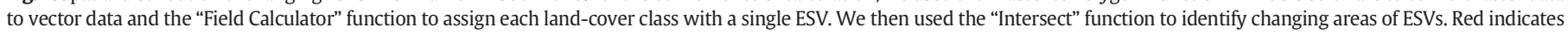

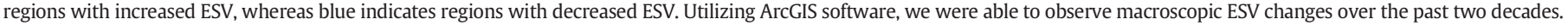




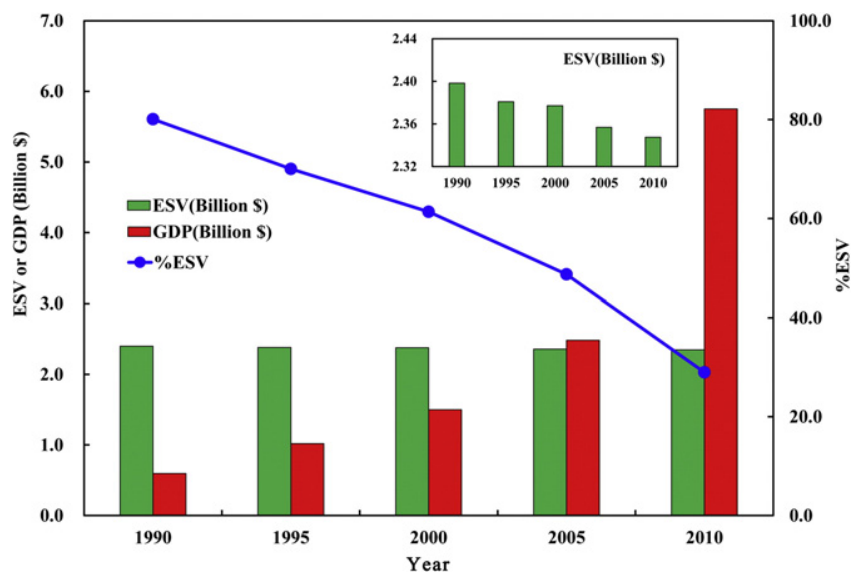

Fig. 3. Changing trends in ESV, GDP and \%ESV in China from 1990-2010. The calculation method to determine \%ESV is described in the Materials and methods section.

\subsection{The relationship between terrestrial ESV and GDP from 1990-2010}

An important objective of this study was to analyze the relationship between economic development and ecosystems represented by two proxy indicators, GDP and ESV, respectively. The overall change trend showed that whereas the corrected GDP displayed exponential growth over time, the ESV continuously decreased (Fig. 3). Assessments and decision making generally require simple and useful indicators to examine and understand the relationship between ESV and GDP (Li and Fang,
2014). Thus, we developed a simple indicator, \%ESV, based on Sutton and Costanza (2002). The \%ESV index results indicate a declining trend, decreasing from 80.09 in 1990 to 28.98 in 2010.

In addition to an analysis of temporal changes, an analysis of spatial variation may provide significant contributions to understanding the relationship between terrestrial ESV and economic development. Therefore, we examined the spatial distribution characteristics and relationships between ESV, GDP, ESV + GDP and \%ESV at the county level (Fig. 4). The results indicate that counties and areas at the top of the list of GDP, such as Tianjin, Hebei, Shandong, Jiangsu and Henan Counties, the Chengdu Plain area and the Pearl River Delta area (comparing Fig. 4a and b), have a lower ESV than other areas. This result demonstrates that for the listed counties, economic development partly caused negative changes in the local ecosystems. Furthermore, this pattern was largely caused by the dominance of lower-value-per-ha ecosystems, such as paddy land, irrigated land and dry land, found in these areas. A higher level of development intensity also contributed to the huge gap between ESVs and GDP. In contrast, most western counties with poor economies have high ESVs. However, we found that the relationship between GDP and ESV is not always fixed. Certain counties with a wealthier economy, including resource-based counties such as Golmud in Qinghai, Alxa League and Ordos in Inner Mongolia, had high ESVs. Fig. 4c shows the spatial distribution of the integrated ESV and GDP values. Because of the addition of ESV, certain regions in western China had a higher integrated value, such as northwest Tibet, eastern Xinjiang, western Qinghai and western and eastern Inner Mongolia. Other high-value areas were distributed over coastal regions and areas in the northeast-central regions of

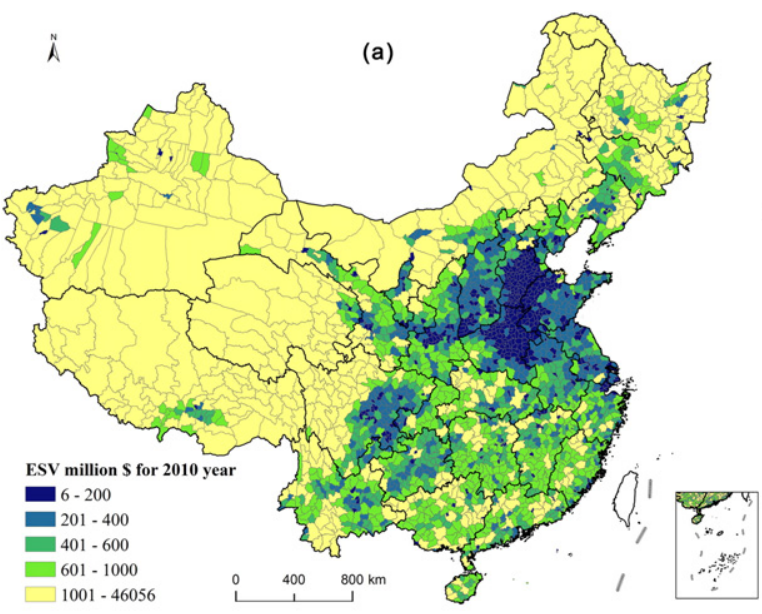

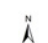

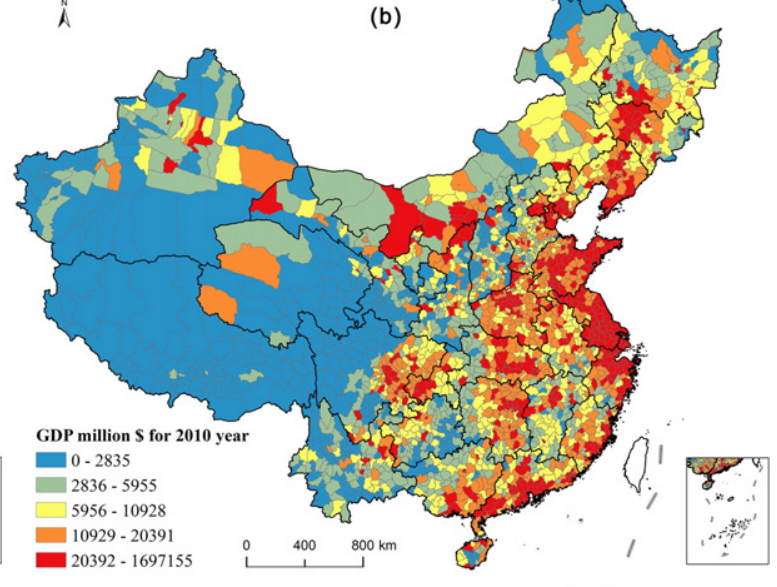

i

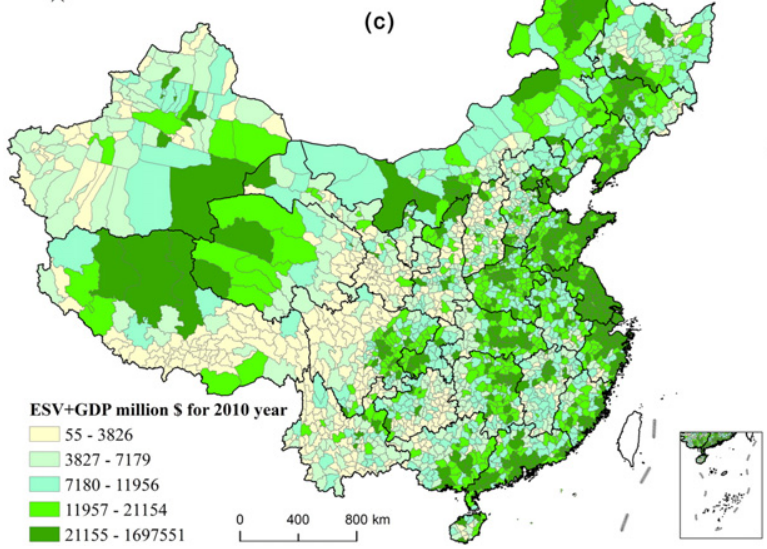

i

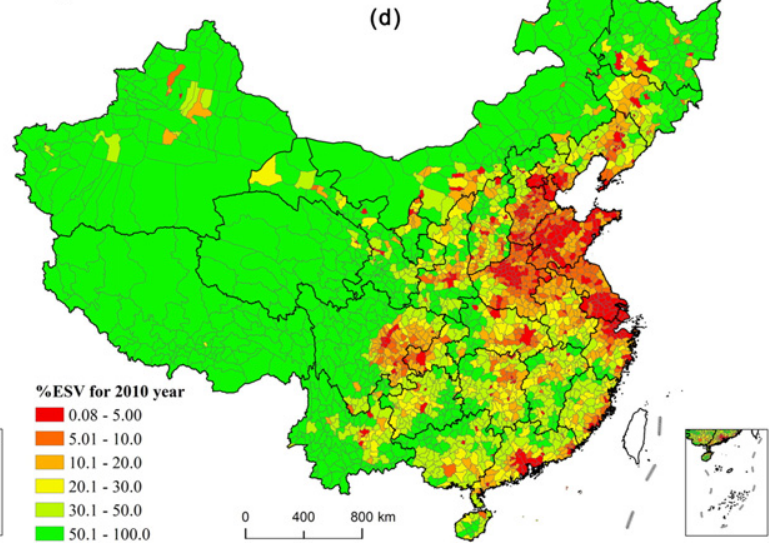

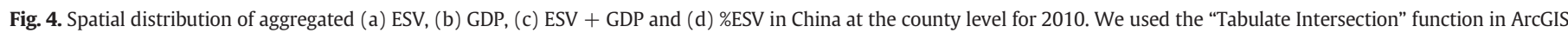
software to summarize the ESV of each county in China and then used the "Field Calculator" function to calculate the ESV + GDP and \%ESV index for each county. 

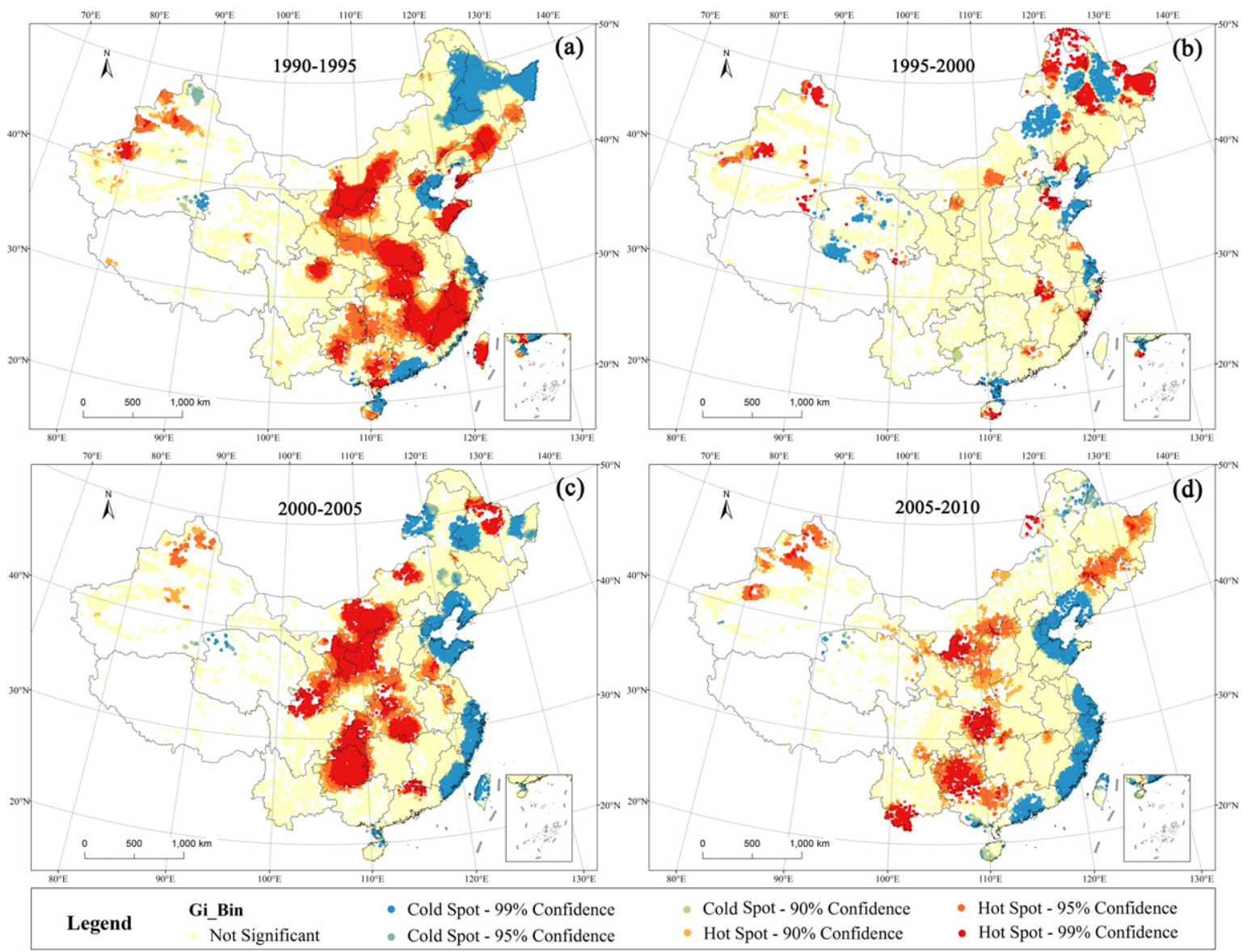

Fig. 5. Spatial distribution of hotspots and cold spots of ESV changes in China from 1990-2010.

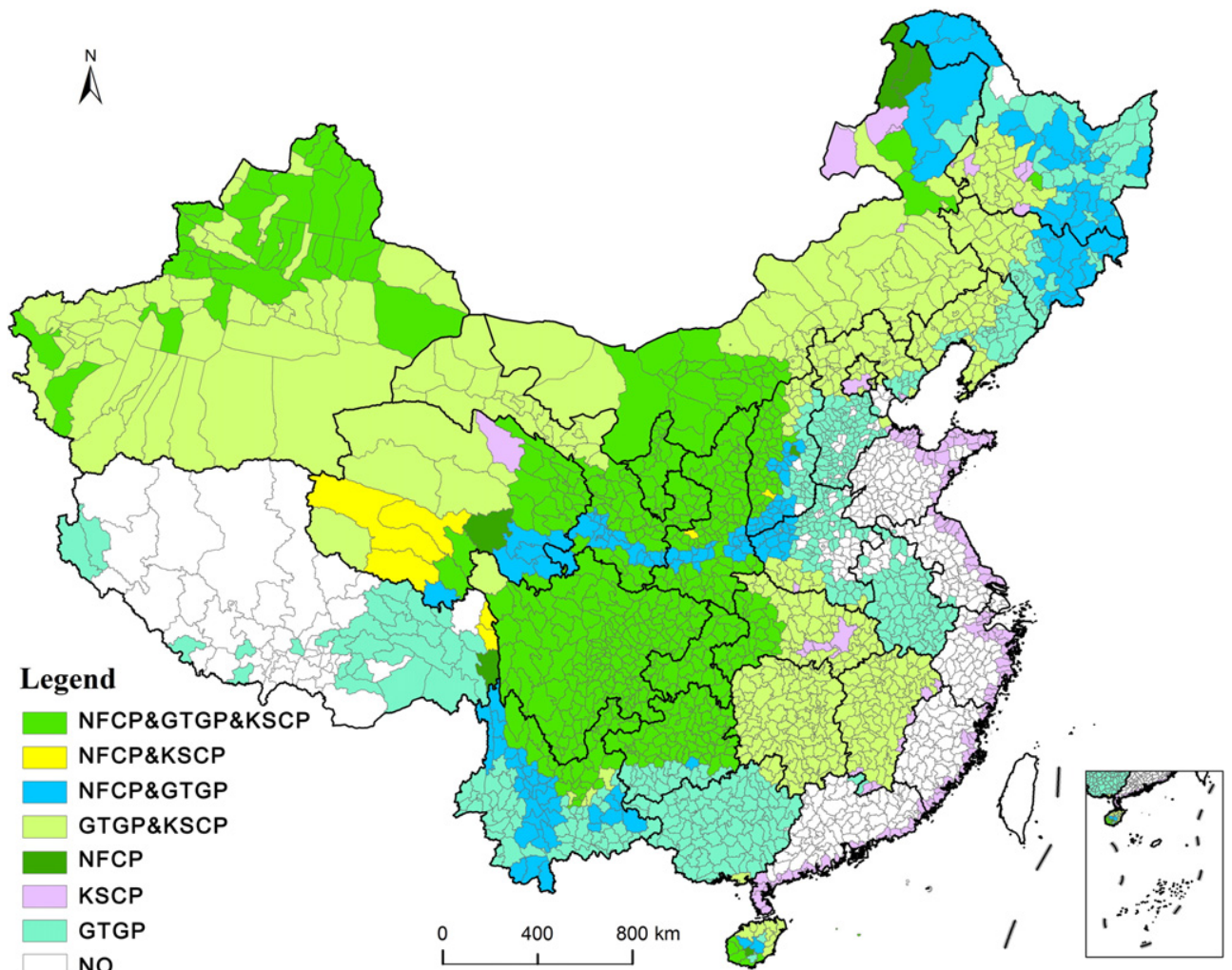

Fig. 6. Current distribution of the NFCP, GTGP and KSCP in China at the county level. 

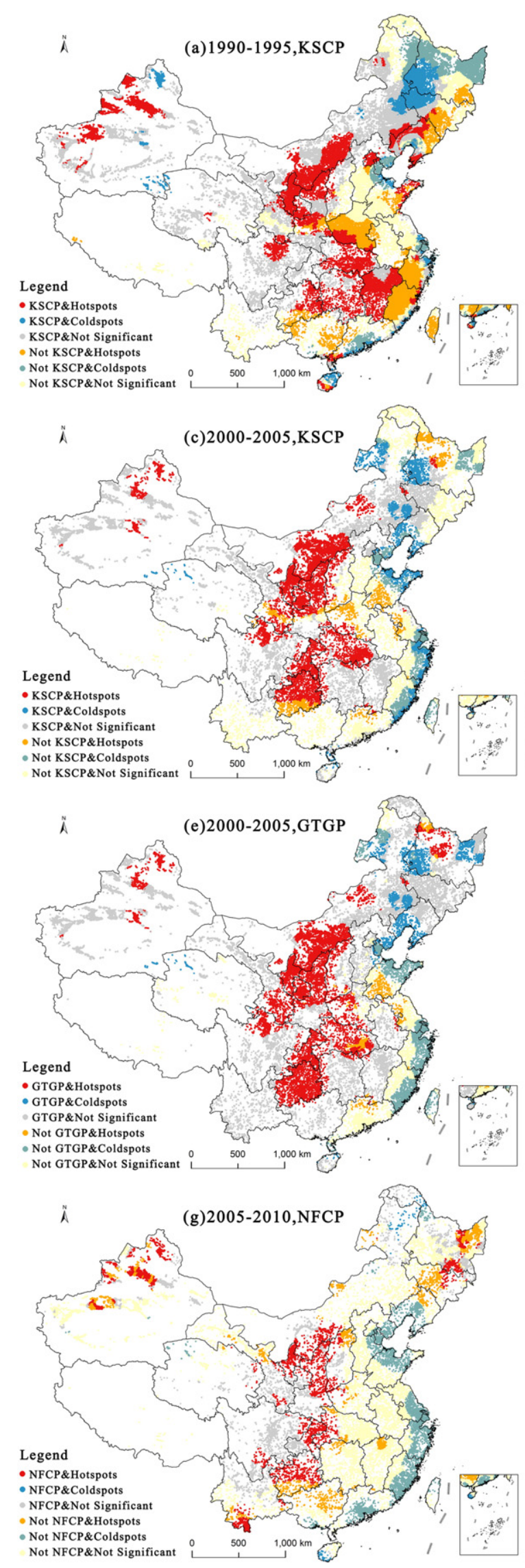
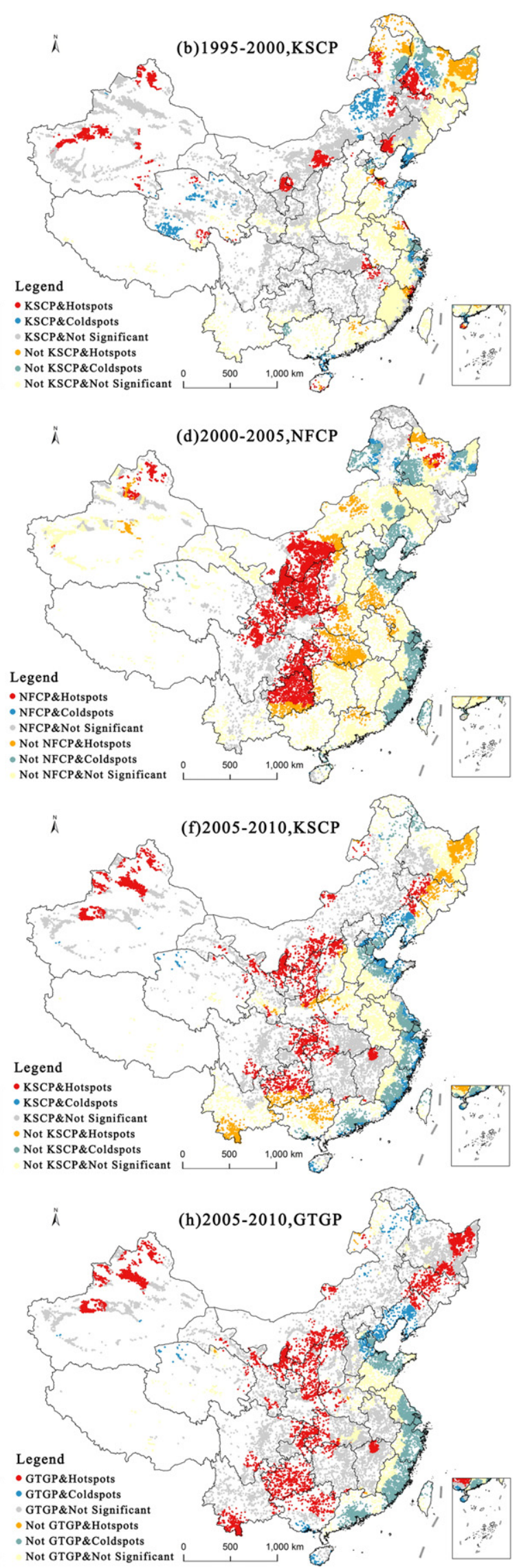

Fig. 7. Overlay areas of ESV hotspots and targeted areas for current national programs on ecosystem service conservation. 
China. However, the low-value areas were primarily located in the southeast, including Tibet, Sichuan, Gansu, Yunnan, Guizhou, Shaanxi and Shanxi. In addition, most high-value and low-value regions were spatially concentrated. Fig. 4d shows a national spatial distribution of \%ESV for each county. We assume that an equal GDP and ESV represent both the need of economic development and the requirement of ecological conservation. Thus, \%ESV can be used as an indicator representing sustainable development. According to this assumption, regions with an \%ESV $<50$ are expected to create immense ecological pressure and continuous deterioration in China. These areas are located in the Beijing-Tianjin-Hebei region, Shandong, Henan, the Yangtze River Delta, Anhui, the Pearl River Delta, and the Chengdu-Chongqing region.

\subsection{Identifying hotspots and cold spots of terrestrial ESV changes and effects of implementing national conservation programs for ecosystem services}

Using the Hot Spot Analysis tool (Getis-Ord Gi*) embedded in ArcGIS software, we identified statistically significant spatial clusters, high values of ESV changes (hotspots) and low values of ESV changes (cold spots), on a national scale. Fig. 5 shows the detailed spatial distribution of hotspots and cold spots based on intersecting points of ESV changes converted from land-cover patches.

For the period 1990 to 1995, hotspot areas were located at the Jilin and Liaoning border region, the Liaodong Peninsula, Beijing, the Inner Mongolia border region, Ningxia, Shaanxi (the Loess Plateau), and eastern Shandong (Fig. 5a). Most of Henan, Hubei, Jiangxi, Fujian and Zhejiang formed an adjacent significant hotspot area with an increased ESV. In addition, eastern Guizhou, the Guangxi and Guangdong border region, north Sichuan and western Xinjiang formed separate multiple hotspots. A comparison of hotspots and national conservation programs for ecosystem services (Fig. 6) showed that the targeted areas of the Key Shelterbelt Construction Program (initiated by the Chinese government in 1978 and composed of seven stages, four of which have been implemented: 1978-1985, 1986-1995, 1996-2000 and 2001-2010) and hotspots identified by changing ESVs had obvious overlapping areas from 1990 to 1995 (Fig. 7). Approximately 63\% of the identified hotspot areas were distributed in targeted areas of the KSCP (Table 2). The coldspot areas were primarily clustered in several regions, including the Sanjiang Plain, the Northeast China Plain, the Bohai Bay region, the Yangtze River Delta, the Pearl River Delta and eastern Hainan. The majority of cold spots were not in the targeted areas of the KSCP, except for the Northeast China Plain. In addition, we found that certain cold spots located in coastal regions were included in the coastal shelterbelt system, which suggests that the coastal shelterbelt system has not achieved the expected conservation results under the pressures of rapid economic development.

Hotspot areas declined sharply in quantity and magnitude between 1995 and 2000 compared with the prior period and were primarily clustered in the Greater Hinggan area, the Sanjiang Plain, western Heilongjiang, the Yellow River Delta, the Anhui, the Hubei and Jiangxi border region, Xinjiang, and several other scattered regions (Fig. 5b). Moreover, the overlay areas of ESV hotspots and targeted areas of the KSCP decreased to 55.73\%, which suggests that the effectiveness of the KSCP during this period was not satisfactory. We also found several significant spatial clusters $(\mathrm{P}<0.10)$ of cold spots located in central Heilongjiang, eastern Inner Mongolia, the Liaodong Peninsula, the Shandong Peninsula, the Yangtze River Delta, the Leizhou Peninsula, and southwest and central Qinghai.

From 2000 to 2005, the spatial agglomeration of ESV changes was significant. Three concentrated hotspots formed in central and western China, including in the Loess Plateau, southeast Gansu, northern Sichuan, Hubei, Chongqing and Guizhou (Fig. 5c). These regions were also targeted areas of the NFCP (which started in 1998 with the overall goal to protect and restore natural forests) and the GTGP (which was initiated by the Chinese government in 1999 and is a large ecosystem service-payment policy). The GTGP has a broader targeted area than the NFCP (Liu et al., 2008). Although time lags were observed in the ecological effects of these programs, the NFCP and GTGP have made outstanding improvements to ecosystems. The KSCP continues to play an important role, although its geographic effect is not as far reaching as that of the GTGP. In addition, our results showed that the overall spatial distribution of cold spots was similar to the former pattern, with coastal regions accounting for the majority of total cold spots, which are continuing to expand.

From 2005 to 2010, hotspot areas declined compared with the period 2000-2005 and were concentrated in the Sanjiang Plain, central Jilin, the Loess Plateau, the Chongqing and Hubei border region, Guizhou, Guangxi, southern Yunnan and Xinjiang (Fig. 5d). The GTGP played an important role in the formation of hotspots, and our results indicated that over $99 \%$ of the hotspot areas and policy-targeted areas overlapped. Conversely, cold spots have continued to expand. Coastal regions account for the most intensive clusters of cold spots, which have produced a concentrated and continuous cold-spot belt.

To gain an even deeper understanding of the direction and magnitude of the effect of conservation programs, we used a logistic regression model to quantitatively test the effects of the KSCP, NSCP and GTGP and to determine the probability of matching these programs with ESV hotspot locations. Table 3 shows that the targeted areas of the KSCP were more likely to be hotspot areas of ESV changes between 1990 and 1995, which provides further evidence for the effectiveness of the KSCP. However, from 1995 to 2000, the effectiveness of the KSCP was not fully realized, and a negative correlation $(\mathrm{P}<0.01)$ was observed between the KSCP and hotspot variables. From 2000 to 2005, the NSCP, GTGP and KSCP variables were significant $(\mathrm{P}<0.01)$, which demonstrates that these policies helped improve the condition of ecosystem services. However, these policies had differential effects. The NSCP had the most influence on the formation of hotspots for ESVs changes, followed by the KSCP and then the GTGP. From 2005 to 2010, significant changes were observed in the effectiveness of these policies $(\mathrm{P}<0.01)$, with the GTGP having the most significant effects on ecological improvement, and the effects of the KSCP tending to weaken.

Overall, the changing pattern of hotspots and cold spots in northeast China has clear temporal characteristics, indicating that the effects of policies on ESV changes fluctuated over time. The Loess Plateau, Guizhou, Hubei, Henan and Xinjiang included consistently concentrated hotspot areas, whereas coastal regions included consistently concentrated

Table 2

Statistical summary for overlapping hotspot areas and targeted program areas.

\begin{tabular}{|c|c|c|c|c|c|}
\hline Period & Program & Number of changing patches & Number of hotspot patches & $\begin{array}{l}\text { Number of overlay patches for hotspot } \\
\text { areas and programs' targeted areas }\end{array}$ & Overlay proportion (\%) \\
\hline 1990-1995 & KSCP & 127,243 & 49,540 & 31,118 & 62.81 \\
\hline 1995-2000 & KSCP & 50,689 & 11,711 & 6527 & 55.73 \\
\hline $2000-2005$ & KSCP & 54,115 & 17,528 & 14,301 & 81.59 \\
\hline $2000-2005$ & NFCP & 54,115 & 17,528 & 12,384 & 70.65 \\
\hline $2000-2005$ & GTGP & 54,115 & 17,528 & 16,064 & 91.65 \\
\hline $2005-2010$ & KSCP & 38,096 & 11,547 & 7083 & 61.34 \\
\hline $2005-2010$ & NFCP & 38,096 & 11,547 & 6974 & 60.40 \\
\hline $2005-2010$ & GTGP & 38,096 & 11,547 & 11,455 & 99.20 \\
\hline
\end{tabular}


Table 3

Logistic regression results for hotspot areas and targeted program areas.

\begin{tabular}{llrlrllr}
\hline Period & Variables & \multicolumn{1}{l}{ B } & S.E. & \multicolumn{1}{l}{ Wald } & df & Sig. & Exp(B) \\
\hline \multirow{2}{*}{$1990-1995$} & KSCP & 0.280 & 0.012 & 566.655 & 1 & 0.000 & 1.324 \\
& Constant & -0.617 & 0.009 & 4552.389 & 1 & 0.000 & 0.540 \\
$1995-2000$ & KSCP & -0.313 & 0.021 & 214.112 & 1 & 0.000 & 0.732 \\
& Constant & -1.016 & 0.016 & 3931.980 & 1 & 0.000 & 0.362 \\
$2000-2005$ & NSCP & 2.131 & 0.023 & 8738.605 & 1 & 0.000 & 8.421 \\
& GTGP & 0.526 & 0.034 & 243.858 & 1 & 0.000 & 1.693 \\
& KSCP & 0.731 & 0.026 & 791.733 & 1 & 0.000 & 2.078 \\
& Constant & -2.604 & 0.031 & 6915.776 & 1 & 0.000 & 0.074 \\
$2005-2010$ & NSCP & 1.237 & 0.025 & 2379.628 & 1 & 0.000 & 3.446 \\
& GTGP & 3.737 & 0.107 & 1229.756 & 1 & 0.000 & 41.985 \\
& KSCP & -0.303 & 0.026 & 133.770 & 1 & 0.000 & 0.739 \\
& Constant & -4.543 & 0.105 & 1872.173 & 1 & 0.000 & 0.011 \\
\hline
\end{tabular}

cold-spot areas. This finding further indicates that spatial grouping is a prominent characteristic of ESV change, and national conservation policies for ecosystem services have promoted clear improvements in ecosystems. Therefore, the results suggest that developing appropriate ecological policies in accordance with local characteristics should be considered to effectively promote positive ecosystem changes.

\section{Discussion}

The study of the dynamic changes in ESVs has highlighted meanings in adjusting national income accounts, identifying overall trends, understanding the relationships between economic development and ecosystem services, and verifying the effects of implementing related ecological conservation programs. The accuracy and confidence level of the analysis results, however, is influenced by the land-cover data accuracy, the ESV valuation method and other relevant constraining conditions, such as system errors in the geographic information system (GIS) spatial analysis. The land-cover data and GDP data used in this paper were obtained from recognized institutions or official statistics, and they are reliable in China. Because data on changes in land cover are the basis of all our research, we focus here on the pros and cons of used land-cover data. CAS national land-cover data have undergone operative dynamic monitoring every five years from 1990 to 2010 . The data will be beneficial to understand long-term changing process of ESVs and similar research themes, such as ecological and environmental changes. Congalton et al. (2014) reported that the accuracy of IGBP DISCover, UMD Land Cover, Global Land Cover 2000, and GlobCover 2009 land cover was 66.9\%, 69\%, 68.6\% and $67.5 \%$, respectively; using this reference as a comparison, we found our dataset has a high total accuracy ( $>80 \%)$. However, we also found several issues in our land-cover dataset: It requires much more time and work to update timely, and there is still room for further improvements in spatial resolutions and accuracy. The present national land-cover data are generally feasible for large-scale studies in China. There is no way to ensure the accuracy of the land-cover information on a finer scale.

To simplify ecosystem-service valuations, we used the benefittransfer method, which is based on a widely approved TEEB dataset. One of the goals of this study was to identify hotspots and cold spots for ESV changes at the national level. Therefore, we adopted the relatively comprehensive benefit-transfer method based on a patch scale to obtain global hotspots of changing ESVs. This method may help avoid information loss caused by the aggregation process (summarizing process from a fine scale to a large scale). To verify the reliability and consistency of our data, we conducted a preliminary validation using the observed \%ESV values at the county level as an example. Further tests were conducted to identify whether each two periods of data (1990 vs 1995, 1995 vs 2000, 2000 vs 2005 and 2005 vs 2010) were consistent using the regression-fitting method. Fig. 8 shows that each scatterplot with the \%ESV values at the county level in China followed quadratic polynomial regression. The goodness of fit $\left(\mathrm{R}^{2}\right)$ of each regression-fitting model was greater than $0.9(\mathrm{P}<0.01)$, indicating that the results of each period are highly consistent. It also indicates that our analysis results are robust and reliable.

\section{(a) \%ESV1990 vs \%ESV1995}

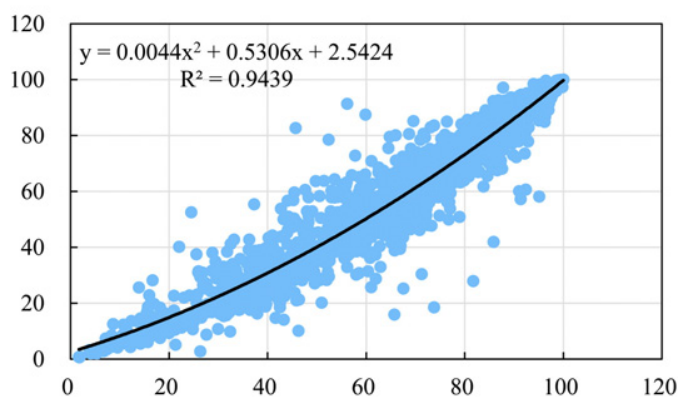

(c) $\%$ ESV200 vs \%ESV2005

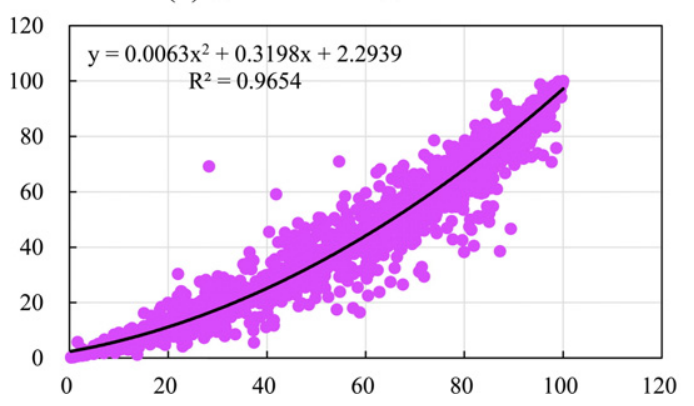

(b) \%ESV1995 vs \%ESV2000

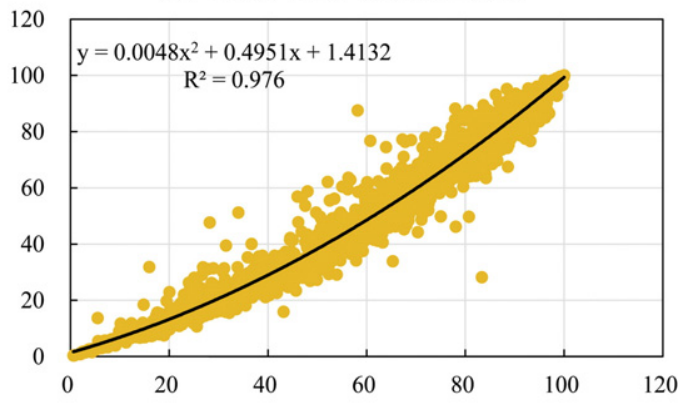

(d) $\%$ ESV2005 vs $\%$ ESV2010

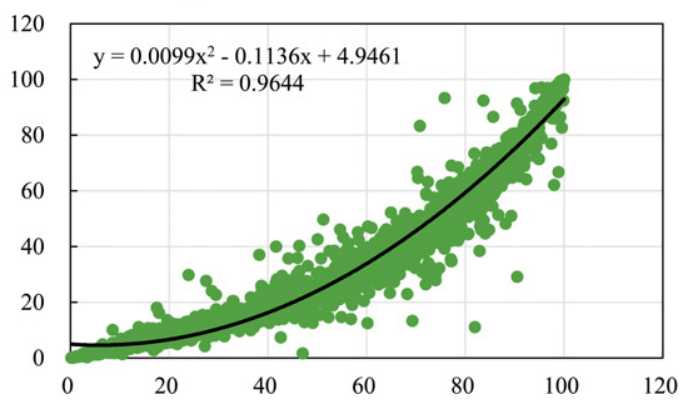

Fig. 8. Consistency test of \%ESV in China at the county level. 
When determining ESVs, the estimation method is of crucial importance. The benefit-transfer method is both widely utilized and widely criticized. Pearce argues that "ecosystem valuation should be linked to the concept of willingness to pay for non-market benefits or to the willingness to accept compensation for non-market costs" (Pearce, 1998). This argument has a degree of rationality. However, we argue that estimating the value of ecosystem services using a value transfer method is a useful method with which to achieve our objectives. On a national scale, the collection of primary data is not feasible because of time and budget constraints (Troy and Wilson, 2006). A benefit-transfer method can be used to quickly estimate the economic value of a particular ecosystem in less time and at a lower cost than with a primary survey. However, more spatially explicit and dynamic methods are preferable and will become essential in future studies (Costanza et al., 2014).

Rapid urbanization, industrialization, economic growth, landdevelopment strategies, and ecological conservation policies are the main factors that have caused ESV changes. China is experiencing a crucial historic period of rapid urbanization and accelerated industrialization. These momentums of development may trigger increased dramatic land-cover changes from a natural landscape to a human-dominated landscape. Hence, we can predict that the total ESVs of China will continue to decline. In recent years, China's government has implemented a series of ecological conservation programs to improve its ecosystems. Thus, we can infer that the speed of ecosystem deterioration will be slowed.

For the hotspot areas of ESV changes, ecological policies should further provide support and ecosystem-service payments for ecological protection to enhance positive ecological and socioeconomic outcomes. For cold-spot areas, the core objective is to address the relationship between economic growth and ecological conservation and to determine an appropriate tradeoff. From a management perspective, we suggest establishing a systematic national ecosystem service-management system to implement real-time, long-term monitoring and to adjust the direction of relevant policies accordingly.

\section{Conclusions}

Our results demonstrated a significant decreasing trend in ESV from 1990 to 2010, with the total ESV decreasing from $\$ 2398.31$ billion in 1990 to $\$ 2347.56$ billion in 2010 (converted to 2009 dollar values). These values indicate the tendency of ecosystems in China to change and gradually deteriorate. However, the decrease in ESV was slight, suggesting that the overall ecosystem integrity had not experienced a sharp decline despite the rapid economic growth in China. The decrease in coastal and inland wetland areas was the main cause of ESV loss. Furthermore, we found that variations in terrestrial ESV change had spatial heterogeneity (a significantly uneven spatial distribution) and observed a significant overlap among land areas with increased or decreased values over time. Our analysis also showed that the \%ESV index has been gradually declining. Overall, economic development leads to negative changes in ecosystems. However, the results presented here show that the relationship between the GDP and ESV was not always fixed. The changing pattern of hotspots and cold spots for ESVs had obvious spatiotemporal characteristics. The Loess Plateau, Guizhou, Hubei, Henan and Xinjiang presented consistently concentrated hotspots areas, whereas coastal regions presented consistently concentrated cold-spot areas. The overlap analyses and logistic regression demonstrated that the KSCP, NFCP and GTGP have had an evident positive ecological effect on China's ecosystems, although the effects of implementing different policies have varied on spatial and temporal scales.

\section{Acknowledgments}

This work was supported by the National Natural Science Foundation of China (grant no. 41590840, 41590842 and 41501175) and the Special Fund for Public Welfare Industry (Ministry of Land and
Resources) (grant no. 201411014-2). The authors thank the comments provided by the two blind reviewers and the editor which were of great value for improving the final version of the manuscript.

\section{References}

Braat, L., ten Brink, P., Bakkes, J., Bolt, K., Braeuer, I., et al., 2008. The cost of policy inaction: the case of not meeting the 2010 biodiversity target. Alterra Report 1718. Wageningen Report for the European Commission, Brussels.

Brander, L.M., Florax, J.G.M., Vermaat, J.E. 2006. The empirics of wetland valuation: a comprehensive summary and meta-analysis of the literature. Environ. Resour. Econ. 33, 223-250

Chan, K.M.A., Shaw, M.R., Cameron, D.R., Underwood, E.C., Daily, G.C., 2006. Conservation planning for ecosystem services. PLoS Biol. (4), e379.

Congalton, R.G., Gu, J., Yadav, K., Thenkabail, P., Ozdogan, M., 2014. Global land cover mapping: a review and uncertainty analysis. Remote Sens. 6 (12), 12070-12093.

Costanza, R., d'Arge, R., Groot, R., Farberk, S., Grasso, M., Hannon, B., et al., 1997. The value of the world's ecosystem services and natural capital. Nature 387, 253-260.

Costanza, R., de Groot, R., Sutton, P., van der Ploeg, S., Anderson, S.J., Kubiszewski, I., et al., 2014. Changes in the global value of ecosystem services. Glob. Environ. Chang. 26, $152-158$.

Diao, X., Zeng, S., Tam, C.M., Tam, V.W., 2009. EKC analysis for studying economic growth and environmental quality: a case study in China. J. Clean. Prod. 17, 541-548.

Egoh, B., Reyers, B., Rouget, M., Bode, M., Richardson, D., 2009. Spatial congruence between biodiversity and ecosystem services in South Africa. Biol. Conserv. 142, 553-562.

Egoh, B.N., Reyers, B., Rouget, M., Richardson, D.M., 2011. Identifying priority areas for ecosystem service management in South African grasslands. J. Environ. Manag. 92, $1642-1650$

ENVAlue, 2004. Environmental Valuation Database (Developed by the) New South Wales Environmental Protection Agency, New Zealand (Available from: http://www. environment.nsw.gov.au/envalue/)

Fang, X., Tang, G., Li, B., Han, R., 2014. Spatial and temporal variations of ecosystem service values in relation to land use pattern in the Loess Plateau of China at town scale. PLoS One 9, e110745.

Fisher, B., Turner, R.K., Morling, P., 2009. Defining and classifying ecosystem services for decision making. Ecol. Econ. 68, 643-653.

de Groot, R.S., Alkemade, R., Braat, L., Hein, L., Willemen, L., 2010. Challenges in integrating the concept of ecosystem services and values in landscape planning, management and decision making. Ecol. Complex. 7, 260-272.

de Groot, R., Brander, L., van der Ploeg, S., Costanza, R., Bernard, F., Braat, L., et al., 2012. Global estimates of the value of ecosystems and their services in monetary units. Ecosyst. Serv. 1, 50-61.

He, Q., Bertness, M.D., Bruno, J.F., Li, B., Chen, G., Coverdale, T.C., et al., 2014. Economic development and coastal ecosystem change in China. Sci. Report. 4

Hu, H.B., Liu, W.J., Cao, M., 2008. Impact of land use and land cover changes on ecosystem services in Menglun, Xishuangbanna, Southwest China. Environ. Monit. Assess. 146, 147-156.

Kreuter, U.P., Harris, H.G., Matlock, M.D., Lacey, R.E., 2001. Change in ecosystem service values in the San Antonio area, Texas. Ecol. Econ. 39, 333-346.

Li, G., Fang, C., 2014. Global mapping and estimation of ecosystem services values and gross domestic product: a spatially explicit integration of national 'green GDP' accounting. Ecol. Indic. 46, 293-314.

Li, T.H., Li, W.K., Qian, Z.H., 2010b. Variations in ecosystem service value in response to land use changes in Shenzhen. Ecol. Econ. 69, 1427-1435.

Li, J.C., Wang, W.L., Hu, G.Y., Wei, Z.H., 2010a. Changes in ecosystem service values in Zoige Plateau, China. Agric. Ecosyst. Environ. 139, 766-770.

Li, R.Q., Dong, M., Cui, J.Y., Zhang, L.L., Cui, Q.G., He, W.M., 2007. Quantification of the impact of land-use changes on ecosystem services: a case study in Pingbian County, China. Environ. Monit. Assess. 128, 503-510.

Liu, J., Li, S., Ouyang, Z., Tam, C., Chen, X., 2008. Ecological and socioeconomic effects of China's policies for ecosystem services. Proc. Natl. Acad. Sci. U. S. A. 105, 9477-9482.

Liu, J., Zhang, Z., Xu, X., Kuang, W., Zhou, W., Zhang, S., et al., 2010. Spatial patterns and driving forces of land use change in China during the early 21st century. J. Geogr. Sci. 20, 483-494.

Liu, J., Zhuang, D., Luo, D., Xiao, X.-m., 2003. Land-cover classification of China: integrated analysis of AVHRR imagery and geophysical data. Int. J. Remote Sens. 24, 2485-2500.

Millennium Ecosystem Assessment, 2005. Ecosystems and Human Well-being: Synthesis. Island Press, Washington, DC

Naidoo, R., Balmford, A., Costanza, R., Fisher, B., Green, R.E., Lehner, B., et al., 2008. Global mapping of ecosystem services and conservation priorities. Proc. Natl. Acad. Sci. 105, 9495-9500.

Pearce, D., 1998. Auditing the earth: the value of the world's ecosystem services and natural capital. Environ. Sci. Pol. Sustain. Dev. 40, 23-28.

Su, C.H., Fu, B.J., He, C.S., Lu, Y.H., 2012a. Variation of ecosystem services and human activities: a case study in the Yanhe Watershed of China. Acta Oecol. 44, 46-57.

Su, S.L., Xiao, R., Jiang, Z.L., Zhang, Y., 2012b. Characterizing landscape pattern and ecosystem service value changes for urbanization impacts at an eco-regional scale. Appl. Geogr. 34, 295-305.

Sundberg, S., Söderqvist, T., 2004. ValueBaseSWE: a Valuation Study Database for Environmental Change in Sweden. Beijer International Institute of Ecological Economics, The Royal Swedish Academy of Sciences, Stockholm (Available from: www.beijer. kva.se/valuebase.htm). 
Sutton, P.C., Costanza, R., 2002. Global estimates of market and non-market values derived from nighttime satellite imagery, land cover, and ecosystem service valuation. Ecol. Econ. 41, 509-527.

TEEB, 2010a. The Economics of Ecosystems and Biodiversity: Ecological and Economic Foundations. Earthscan, London, Washington.

TEEB, 2010b. Mainstreaming the Economics of Nature: a Synthesis of the Approach Conclusions and Recommendations of TEEB. Earthscan, London, Washington.

Troy, A., Wilson, M.A., 2006. Mapping ecosystem services: practical challenges and opportunities in linking GIS and value transfer. Ecol. Econ. 60, 435-449.

Turner, W.R., Brandon, K., Brooks, T.M., Costanza, R., Da Fonseca, G.A., Portela, R., 2007. Global conservation of biodiversity and ecosystem services. Bioscience 57, 868-873.
UVM, 2008. Ecosystem Service Database (ESD)/ARIES (Developed by) University of Vermont, USA (Available from: http://esd.uvm.edu/).

Wan, L.L., Ye, X.Y., Lee, J., Lu, X.Q., Zheng, L., Wu, K.Y., 2015. Effects of urbanization on ecosystem service values in a mineral resource-based city. Habitat Int. 46, 54-63.

Wilson, M.A., Costanza, R., Troy, A., 2004. The EcoValue Project (Retrieved from the) University of Vermont EcoValue (Available from: http://ecovalue.uvm.edu).

Zhao, B., Kreuter, U., Li, B., Ma, Z.J., Chen, J.K., Nakagoshi, N., 2004. An ecosystem service value assessment of land-use change on Chongming Island, China. Land Use Policy $21,139-148$. 